\title{
TEKNIK KOOPERATIF TERPADU MEMBACA DAN MENULIS PADA MATERI MENULIS SURAT DI KELAS VI SDN 1 KRANDON
}

\author{
Asti \\ SDN 1 Kerandon Cirebon, Indonesia \\ asti0313@gmail.com
}

\begin{abstract}
The study began with a problem faced by the teacher, namely the lack of students' ability to understand the material. This study aims to improve the ability of Grade VI students of SDN 1 Kerandon in understanding Indonesian subjects on the material "Technology" with the subject "Writing Letters" through the application of Integrated Cooperative Techniques in Reading and Writing, so that learning Indonesian becomes more enjoyable and creates creativity. The method used is Classroom Action Research (CAR) carried out in class VI of SD Negeri 1 Kerandon Cirebon Regency. The activities were carried out in two cycles of action. The results showed that the application of the Integrated Reading and Writing Cooperative Technique can Improve Students' Understanding of Indonesian Language "Writing Letters" in Class VI SD Negeri 1 Kerandon, Talun District, Cirebon Regency.
\end{abstract}

Keywords: learning outcomes, integrated cooperative techniques, reading and writing.

\begin{tabular}{l}
\hline ABSTRAK \\
\hline Penelitian ini diawalai dengan masalah yang dihadapi guru yaitu masih kurangnya kemampuan \\
siswa dalam memahami materi. Penelitian ini bertujuan untuk meningkatkan kemampuan siswa \\
kelas VI SDN 1 Kerandon dalam memahami mata pelajaran Bahasa Indonesia pada materi \\
"Teknologi" dengan pokok bahasan "Menulis Surat" melalui penerapan Teknik Kooperatif \\
Terpadu Membaca dan Menulis, sehingga pembelajaran Bahasa Indonesia menjadi lebih \\
menyenangkan dan menimbulkan kreatifitas. Metode yang digunakan adalah Penelitian \\
Tindakan Kelas (PTK) dengan dilaksanakan pada kelas VI SD Negeri 1 Kerandon Kabupaten \\
Cirebon. Kegiatan dilakukan sebanyak dua siklus tindakan. Hasil penelitian menunjukkan \\
penerapan Teknik Kooperatif Terpadu Membaca dan Menulis dapat Meningkatkan Pemahaman \\
siswa dalam belajar Bahasa Indonesia "Menulis Surat" di Kelas VI SD Negeri 1 Kerandon \\
Kecamatan Talun Kabupaten Cirebon.
\end{tabular}

Kata Kunci: hasil belajar, teknik kooperatif terpadu, membaca dan menulis.

Submitted Feb 25, 2020 | Revised Mar 22, 2020 | Accepted Mar 24, 2020

\section{Pendahuluan}

Pembelajaran Bahasa Indonesia ada empat keterampilan yaitu keterampilan berbicara, menyimak, menulis dan keterampilan membaca. Sekolah Dasar (SD). Keterampilan menulis sebagai salah satu komponen dari keterampilan berbahasa mempunyai peran penting dalam kehidupan. Menurut Nurudin (2010) menulis bermanfaat untuk (1) sarana mengungkapkan diri, yakni bahwa dengan menulis bisa mengungkapkan perasaan hati (kegelisahan, keinginan, kemarahan dan lain-lain); (2) sarana pemahaman, yakni menulis sebenarnya menancapkan pemahaman kuat dalam otak penulis; (3) membantu mengembangkan kepuasan pribadi, kebanggaan, perasaan harga diri; (4) meningkatkan kesadaran dan penyerapan terhadap lingkungan; (5) keterlibatan secara bersemangat dan bukannya penerimaan yang pasrah; (6) 
mengembangkan suatu pemahaman tentang dan kemampuan menggunakan bahasa. Bagi sebagian besar anak yang tinggal di pedesaan, kegiatan belajar untuk mendengarkan, berbicara, membaca, dan menulis dengan menggunakan bahasa Indonesia yang baik dan benar masih kurang. Seperti anak dalam mendengarkan, membaca atau menulis tentang informasi atau berita dari media cetak maupun elektronik masih belum mampu untuk menyimak atau menanggapi hal tersebut yang disusun dalam sebuah laporan.

Dalam proses pembelajaran siswa dituntut aktif, dimana siswa banyak melakukan kegiatan, sedangkan guru lebih banya membimbing dan mengarahkan. Menurut Yamin (2007: 80-81) menjelaskan bahwa keaktifan siswa dapat dilaksanakan manakala: (1) pembelajaran yang dilakukan lebih berpusat pada siswa, (2) guru berperan sebagai pembimbing supaya terjadi pengalaman dalam belajar, (3) tujuan kegiatan pembelajaran tercapai kemampuan minimal siswa (kompetensi dasar), (4) pengelolaan kegiatan pembelajaran lebih menekankan pada kreativitas siswa, meningkatkan kemapuan minimalnya, dan mencapai siswa yang kreatif serta mampu menguasai konsep-konsep, dan (5) melakuan pengukuran secara kontinu dalam berbagai aspek pengetahuan, sikap, dan keterampilan.

Siswa aktif adalah siswa yang terlibat secara intelektual dan emosional dalam kegiatan belajar (Ahmadi \& Supriyono, 2004: 207). Siswa aktif adalah siswa yang terlibat secara fisik, psikis, intelektual dan emosional secara terus menerus dalam proses pembelajaran (Yusmiati, 2010). Keaktifan siswa dalam proses pembelajaran tidak hanya keterlibatan dalam bentuk fisik seperti duduk melingkar, mengerjakan/ melakukan sesuatu, akan tetapi dapat juga dalam bentuk proses analisis, analogi, komparasi, penghayatan, yang kesemuanya merupakan keterlibatan siswa dalam hal psikis dan emosi (Sugandi, 2007). Dari pengertian-pengertian tersebut dapat disimpulkan bahwa siswa aktif adalah siswa yang terlibat secara terus menerus baik secara fisik, psikis, intelektual maupun emosional dalam proses pembelajaran.

Tarigan (dalam Samsudin, 2012:2) berpendapat bahwa keterampilan menulis dapat dikuasai dan dapat diperoleh melalui jalan praktikdan latihan yang sistematis. Sementara itu menurut Andayani (2009:29) mengemukakan bahwa menulis merupakan aktivitas melahirkan pikiran dan perasaan lewat tulisan dengan memperhatikan aspek-aspek kebahasaan yang baik dan benar sehingga dapat dipahami oleh pembaca.

Sejalan dengan persoalan di atas dalam proses belajar mengajar Bahasa Indonesia diperlukan metode-metode baru yang inovatif yang dapat membawa siswa kearah belajar yang lebih baik dan bersemangat tinggi. Oleh karena itu harus dicari metode-metode baru yang tepat yang dapat menarik siswa kearah belajar yang lebih baik dan bersemangat dalam mempelajari Bahasa Indonesia, salah satunya adalah Teknik Kooperatif Terpadu Membaca dan Menulis. Beberapa penelitian yang telah dilaksanakan, diantaranya oleh Saputri, dkk. (2016), Niliawati (2018), Sampepolan (2019) menunjukan penerapan Teknik Kooperatif Terpadu Membaca dan Menulis dapat meningkatkan kemampuan menulis dan hasil belajar siswa. Atas dasar itulah penulis memilih teknik ini sebagai upaya meningkatkan kemampuan menulis siswa.

Penelitian ini akan difokuskan pada upaya untuk mengatasi faktor internal yang diduga menjadi penyebab rendahnya tingkat kemampuan siswa kelas VI SD Negeri 1 Jermaras Lor Kecamatan Talun Kabupaten Cirebon, memahami dalam mata pelajaran Bahasa Indonesia, yaitu kurangnya inovasi dan kreativitas guru dalam menggunakan metode pembelajaran sehingga kegiatan pembelajaran Bahasa Indonesia berlangsung monoton dan membosankan. 
Salah satu metode pembelajaran yang diduga mampu mewujudkan situasi pembelajaran yang kondusif, aktif, kreatif, efektif, dan menyenangkan adalah Teknik Kooperatif Terpadu Membaca dan Menulis.

Tujuan penerapan Teknik Kooperatif Terpadu Membaca dan Menulis, diharapkan untuk mencapai setidak-tidaknya tiga tujuan pembelajaran, yaitu hasil belajar akdemik, penerimaan terhadap keragaman, dan pengembangan keterampilan sosial. Beberapa ahli berpendapat bahwa pembelajaran ini unggul dalam membantu siswa memahami konsepkonsep sulit.

\section{Metode Penelitian}

Penelitian ini merupakan Penelitian Tindakan Sekolah yang dilakukan secara kolaborasi. Penelitian Tindakan Sekolah berdasarkan pendapat Sanjaya (2011: 26) adalah proses pengkajian masalah pembelajaran di dalam kelas melalui refleksi diri dalam upaya untuk memecahkan masalah tersebut dengan cara melakukan tindakan yang terencana dalam situasi nyata serta menganalisis setiap pengaruh dari perlakuan tersebut. Pendapat tersebut sesuai pendapat yang disampaikan oleh Kasbolah (2001: 15), bahwa Penelitian Tindakan Sekolah merupakan penelitian tindakan dalam bidang pendidikan yang dilaksananakan dalam kawasan kelas dengan tujuan untuk memperbaiki dan atau meningkatkan kualitas pembelajaran.

Banyak model Penelitian Tindakan Sekolah yang dapat diterapkan, tetapi dalam penelitian ini menggunakan model Kemmis dan McTaggart di mana dalam perencanaannya menggunakan siklus sistem spiral yang di dalamnya terdiri dari empat komponen, yaitu rencana, tindakan dan observasi serta refleksi (Sujati, 2000: 23).

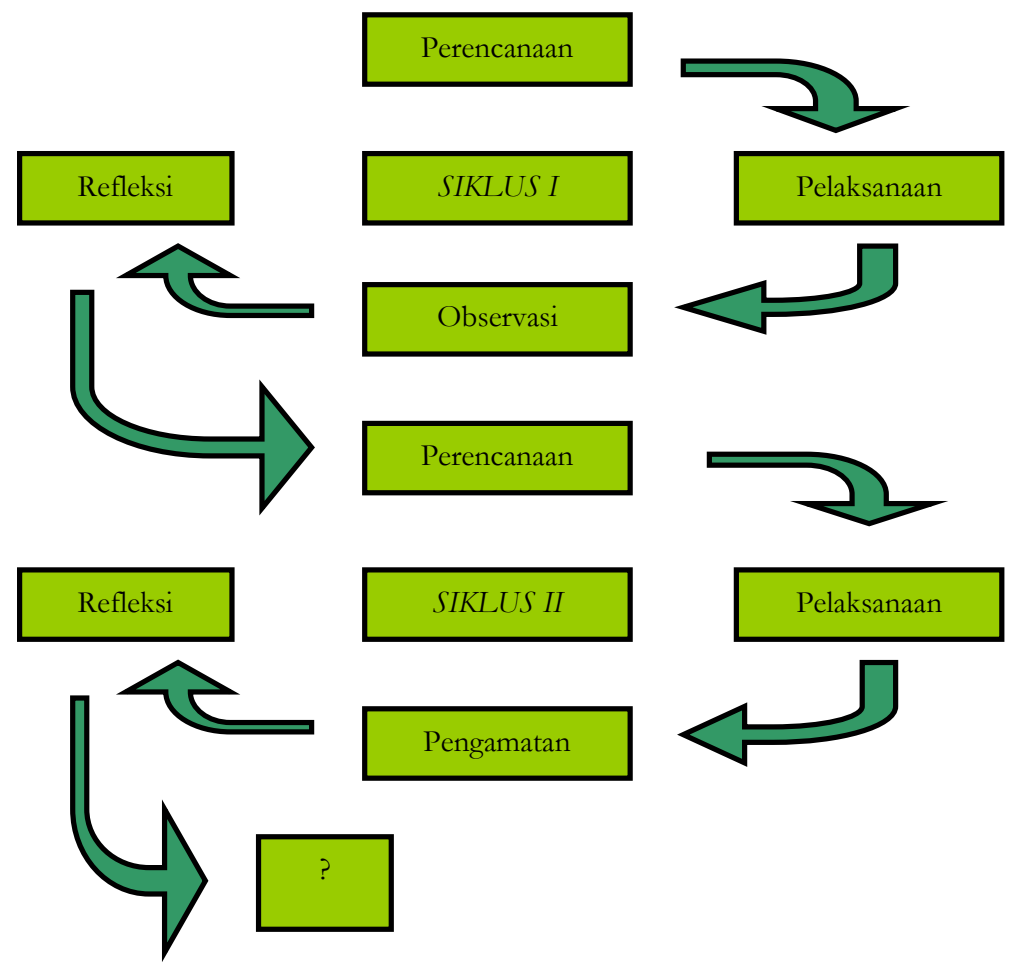

Gambar 1. Model PTK kemmis dan Mc Taggart 
Penelitian tindakan kelas ini dilaksanakan di Kelas VI SD Negeri 1 Kerandon Kecamatan Talun Kabupaten Cirebon semester kedua tahun 2018/2019 hal ini disebabkan Pemahaman siswa dalam belajar Bahasa Indonesia pada materi "Menulis Surat" masih kurang, sehingga berdampak pada prestasi belajarnya masih di bawah standar KKM 70. Maka Perlu adanya penelitian tentang pendekatan pembelajaran yang paling efektif sehingga prestasi dalam mata pelajaran Bahasa Indonesia siswa tersebut sesuai apa yang diharapkan.

Subjek penelitian tindakan kelas ini adalah siswa kelas VIB SD Negeri 1 Kerandon tahun ajaran 2018 - 2019 sebanyak 28 siswa. Dalam pengambilan subyek penelitian ini didasarkan pada kondisi kelas VIB secara keseluruhan. Dalam penelitian ini asumsikan karakteristik dan kemampuan dianggap sama.

Data penelitian ini menggunakan pendekatan kuantitatif dan kualitatif secara bersamasama. Pendekatan kualitatif digunakan untuk memberikan deskripsi tentang pandangan dan pendapat dari subyek penelitian. Pendekatan kuantitatif digunakan dengan cara mencatat peristiwa hasil prestasi belajar siswa sebelum adanya penelitian, kemudian diadakannya penelitian tindakan kelas pada siklus pertama dan kedua. Dengan pengelompokan data, maka akan ditemukan nilai rendah dan nilai tinggi serta ditemukan nilai rata-rata dari sebelum adanya penelitian tindakan kelas, ketika diadakan dan ada perbaikan.

Prosedur penelitian tindakan kelas dilakukan dengan dua siklus. Setiap siklus direncanakan dan dilaksanakan untuk meningkatkan mutu proses pembelajaran di SDN 1 Kerandon dengan cara membahas dan mempelajari masalah-masalah dengan berdiskusi dan akan berdampak pada meningkatnya prestasi belajar. Data keefektifan dan ketidak efektifan tindakan siswa selama proses pembelajaran diperoleh melalui pengamatan terhadap interaksi siswa dengan siswa atau dengan komponen yang lainnya. Data tentang ketercapaian indikator hasil belajar dari setiap kelompok diperoleh melalui pengamatan terhadap hasil kerja siswa selama proses pembelajaran dan presentasi hasil belajar.

Data tersebut sebagai bahan refleksi untuk dicarikan, ditemukan, dan ditetapkan tindakan-tindakan perbaikan dan solusinya berdasarkan teori penerapan Teknik Kooperatif Terpadu Membaca dan Menulis dengan tujuan untuk mengatasi tindakan-tindakan siswa yang tidak efektif dan meningkatkan mutu tindakan-tindakan siswa agar menjadi lebih efektif. Dengan berpedoman dengan hasil refleksi tersebut, penelitian tindakan kelas dilakukan dengan prosedur 1) perencanaan, 2) pelaksanaan, 3) observasi dan 4) refleksi dalam setiap siklus.

\section{Hasil dan Pembahasan}

Kegiatan pembelajaran pada penelitian ini dilaksanakan dalam 2 siklus, masing-masing siklus terdiri dari studi pendahuluan, perencanaan, tindakan, observer dan refleksi kegiatan yang dilaksanakan. Pada awal pembelajaran guru memberikan motivasi yang menuntun siswa untuk mengingat kembali materi yang akan dibahas, memberikan motivasi kepada siswa agar ikut aktif berperan serta dalam proses belajar, serta menginformasikan tentang kompetensi yang harus dikuasai, menggunakan Teknik Kooperatif Terpadu Membaca dan Menulis pada mata pelajaran yang akan dilaksanakan. Dari setiap kelompok belajar siswa kelas VIB SDN 1 Kerandon Kecamatan Talun Kabupaten Cirebon, dalam pembelajaran Bahasa Indonesia pada materi "Menulis Surat" melalui penerapan Teknik Kooperatif Terpadu Membaca dan Menulis diperoleh hasil evaluasi selama siklus I dan II sebagai berikut: 
Tabel 1. Nilai Evaluasi Siklus I

\begin{tabular}{|c|c|c|c|c|}
\hline No & $\mathbf{N}$ a m a & $\mathbf{L} / \mathbf{P}$ & Pra test & Siklus I \\
\hline 1 & Prian Adianto & $\mathrm{L}$ & 40 & 50 \\
\hline 2 & Moch. Febri Yuwana & $\mathrm{L}$ & 40 & 60 \\
\hline 3 & Dwiki Rizki & $\mathrm{P}$ & 60 & 60 \\
\hline 4 & Amud Riyansyah & $\mathrm{L}$ & 60 & 70 \\
\hline 5 & Andi Maulana & $\mathrm{L}$ & 50 & 60 \\
\hline 6 & Ahmad Fajar & $\mathrm{L}$ & 60 & 70 \\
\hline 7 & Arif Abdurrahman & $\mathrm{L}$ & 50 & 60 \\
\hline 8 & Citra Permata Amelia & $\mathrm{P}$ & 50 & 60 \\
\hline 9 & Fakih Maulana & $\mathrm{L}$ & 40 & 60 \\
\hline 10 & Fifit Fitria Rosiana & $\mathrm{P}$ & 70 & 80 \\
\hline 11 & Handika Firdaus & $\mathrm{L}$ & 60 & 70 \\
\hline 12 & Hardi Budiyanto & $\mathrm{L}$ & 60 & 70 \\
\hline 13 & Heri & $\mathrm{L}$ & 50 & 60 \\
\hline 14 & Heryani & $\mathrm{P}$ & 50 & 60 \\
\hline 15 & Isnaeni Asifah & $\mathrm{P}$ & 60 & 60 \\
\hline 16 & Muhammad Alif Hendrawan & $\mathrm{L}$ & 40 & 60 \\
\hline 17 & Mohammad Aditia Dermawan & $\mathrm{L}$ & 50 & 70 \\
\hline 18 & Miftahus Surur & $\mathrm{L}$ & 40 & 60 \\
\hline 19 & Nata Kusuma & $\mathrm{P}$ & 70 & 70 \\
\hline 20 & Resi Nurliya & $\mathrm{P}$ & 50 & 60 \\
\hline 21 & Ririn Permatasari & $\mathrm{P}$ & 40 & 60 \\
\hline 22 & Rusyani & $\mathrm{P}$ & 50 & 60 \\
\hline 23 & Sri Ayuni & $\mathrm{P}$ & 70 & 80 \\
\hline 24 & Siti Aisyah & $\mathrm{P}$ & 40 & 60 \\
\hline 25 & Siti Solehah & $\mathrm{P}$ & 50 & 60 \\
\hline 26 & Siti Rofi'ah & $\mathrm{P}$ & 40 & 50 \\
\hline 27 & Soni & $\mathrm{L}$ & 40 & 60 \\
\hline 28 & Rifal & $\mathrm{L}$ & 60 & 60 \\
\hline \multicolumn{3}{|c|}{ Jumlah } & 1440 & 1760 \\
\hline \multicolumn{3}{|c|}{ Rata-rata } & 51,43 & 62,86 \\
\hline
\end{tabular}

Tingkat pencapaian penguasaan materi Bahasa Indonesia tentang "Menulis Surat" mengalami peningkatan dengan rata-rata 51,43 pada pra test, dan mencapai rata-rata 62,86 pada hasil evaluasi pasca test.

Tabel 2. Nilai Evaluasi Siklus II

\begin{tabular}{clccc}
\hline No & Nama & L/P & Siklus I & Siklus II \\
\hline 1 & Prian Adianto & L & 50 & 70 \\
2 & Moch. Febri Yuwana & L & 60 & 80 \\
3 & Dwiki Rizki & P & 60 & 80 \\
4 & Amud Riyansyah & L & 70 & 80 \\
5 & Andi Maulana & L & 60 & 80 \\
6 & Ahmad Fajar & L & 70 & 80 \\
7 & Arif Abdurrahman & L & 60 & 80 \\
8 & Citra Permata Amelia & P & 60 & 80 \\
\hline
\end{tabular}




\begin{tabular}{clccc}
\hline 9 & Fakih Maulana & L & 60 & 80 \\
10 & Fifit Fitria Rosiana & $\mathrm{P}$ & 80 & 90 \\
11 & Handika Firdaus & $\mathrm{L}$ & 70 & 90 \\
12 & Hardi Budiyanto & $\mathrm{L}$ & 70 & 80 \\
13 & Heri & $\mathrm{L}$ & 60 & 80 \\
14 & Heryani & $\mathrm{P}$ & 60 & 70 \\
15 & Isnaeni Asifah & $\mathrm{P}$ & 60 & 80 \\
16 & Muhammad Alif Hendrawan & $\mathrm{L}$ & 60 & 80 \\
17 & Mohammad Aditia Dermawan & $\mathrm{L}$ & 70 & 80 \\
18 & Miftahus Surur & $\mathrm{L}$ & 60 & 70 \\
19 & Nata Kusuma & $\mathrm{P}$ & 70 & 90 \\
20 & Resi Nurliya & $\mathrm{P}$ & 60 & 80 \\
21 & Ririn Permatasari & $\mathrm{P}$ & 60 & 70 \\
22 & Rusyani & $\mathrm{P}$ & 60 & 80 \\
23 & Sri Ayuni & $\mathrm{P}$ & 80 & 90 \\
24 & Siti Aisyah & $\mathrm{P}$ & 60 & 80 \\
25 & Siti Solehah & $\mathrm{P}$ & 60 & 80 \\
26 & Siti Rofi'ah & $\mathrm{P}$ & 50 & 70 \\
27 & Soni & $\mathrm{L}$ & 60 & 80 \\
28 & Rifal & $\mathrm{L}$ & 60 & 80 \\
& & & 1760 & 2230 \\
& & & 62,86 & 79,65 \\
\hline
\end{tabular}

Tingkat pencapaian penguasaan materi Bahasa Indonesia tentang "Menulis Surat" mengalami peningkatan dengan rata-rata 62,86 pada pra test menjadi rata-rata 79,65 pada hasil evluasi pasca test. Dari data hasil pembahasan secara kuantitatif terhadap hasil pretest dan post test siswa dalam belajar Bahasa Indonesia pada materi "Menulis Surat" yaitu Hasil awal menunjukkan skor rata-rata sebesar 51,43, hasil pada siklus I meningkat menjadi skor rata-rata sebesar 62,86, Hasil pada siklus II naik menjadi skor rata-rata sebesar 79,65. Dengan demikian, meningkatnya nilai dari hasil evaluasi belajar siswa dalam mata pelajaran Bahasa Indonesia pada materi "Menulis Surat" pada tiap siklusnya, berarti pemahaman siswa Kelas VI SDN 1 Kerandon pada materi tersebut menunjukkan adanya peningkatan yang cukup signifikan. Hal ini dapat dilihat melalui diagram grafik.

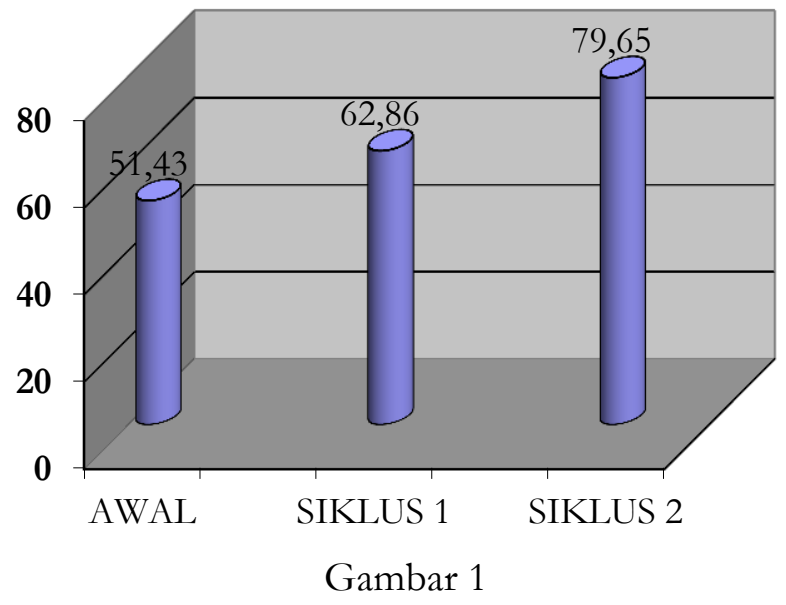

Diagram Grafik Peningkatan Pemahaman Siswa 
Berdasarkan pengamatan diperoleh beberapa temuan diantaranya adalah siswa yang bisa menjawab pertanyaan atau permasalahan meningkat, siswa yang menyampaikan pendapat meningkat, siswa yang memperhatikan secara aktif meningkat, Siswa yang mengajukan pertanyaan atau mengungkapkan permasalahan cukup meningkat, siswa yang bekerja dan belajar secara aktif, pada siklus I mencapai persentase sebesar $48 \%$ adapun pada siklus II mencapai persentase $76 \%$. Adapun kinerja guru dalam kegiatan pembelajaran Bahasa Indonesia pada materi "Menulis Surat" pada siklus I menunjukkan persentase $50 \%$ (cukup baik), pada siklus II naik dengan persentase sebesar $92 \%$ (baik).

\section{Kesimpulan}

Berdasarkan hasil penelitian yang dijelaskan di atas dapat disimpulkan bahwa penerapan Teknik Kooperatif Terpadu Membaca dan Menulis dapat Meningkatkan Pemahaman siswa dalam belajar Bahasa Indonesia pada materi "Menulis Surat" di Kelas VI SD Negeri 1 Kerandon Kecamatan Talun Kabupaten Cirebon.

\section{Daftar Pustaka}

Ahmadi, A. \& Supriyono W.( 2004). Psikologi Belajar. Jakarta: Rineka Cipta.

Kasbolah (2001). Penelitian Tindakan Kelas. Jakarta: Bumi Aksara.

Niliawati, L, dkk. (2018). Penerapan Metode Circ (Cooperative Integrated Reading And Composition) Untuk Meningkatkan Kemampuan Membaca Pemahaman Siswa Kelas IV. Jurnal Pendidikan Guru Sekolah Dasar, 3(1), 23-34.

Nurudin. (2010). Dasar-Dasar Penulisan. Malang: UMM Press.

Sampepolan, YA. (2019). Meningkatkan Hasil Belajar PKn pada Materi Nilai dan Norma Sosial Melalui Pembelajaran CIRC (Cooperative, Integrated, Reading, And Composition) pada Siswa Kelas VIII2 SMP Negeri 1 Rantepao Toraja Utara. Jurnal Pemikiran dan Pengembangan Pembelajaran, 1(1), 130-139.

Samsudin, A. (2011).Peningkatan Kemampuan Menulis Eksposisi Berita dan Menulis Eksposisi Ilustrasi Siswa Kelas V Melalui Model Pembelajaran Kooperatif Terpadu Membaca dan Menulis. Jurnal Penelitian Pendidikan. 13 (2)1-9.

Sanjaya. (2010). Penelitian Tindakan Sekolah. Jakarta: Kencana.

Saputri, dkk. (2016). Penerapan Metode Cooperative Integrated Reading And Composition Dengan Media Audio Visual Untuk Meningkatkan Kemampuan Menulis Teks Berita Pada Siswa Sekolah Menengah Pertama. BASASTRA Jurnal Penelitian Bahasa, Sastra Indonesia dan Pengajarannya. 4(2), 145-160.

Sugandi, A.( 2004). TeoriPembelajaran. Semarang: UNNES Press.

Sujati. (2000). Penelitian Tindaka Kelas. Yogyakarta. FIP. UNY.

Yamin, M. (2007). Profesionalisasi Guru \& Implementasi KTSP. Jakarta: Gaung. Persada Press.

Yusmiati, E. 2010. Penerapan Model Siklus Belajar Empiris Induktif Untuk. Meningkatkan Aktivitas dan Penguasaan Konsep Larutan Elektrolit dan Reaksi. Bandar Lampung : Universitas Lampung. 